\title{
Pendapatan dan kelayakan usahatani cabai rawit
}

\author{
Yuhanin Zamrodah $^{1 *}$, Lintar Brillian Pintakami ${ }^{1}$ \\ ${ }^{1}$ Program Studi Agribisnis, Fakultas Pertanian, Universitas Islam Balitar, Blitar, Jawa Timur, Indonesia \\ *E-mail: yuhaninzamrodah@unisbablitar.ac.id
}

\begin{abstract}
Indonesia is an agrarian country, one of which produces a chili commodity that can support the economy in this country. Chili is one type of horticulture that cannot be left by the community in everyday life. Besides that, chili farming has very good prospects. The purpose of this study was to determine the revenue, income obtained by farmers in one planting season, and the feasibility of chili farming in one season. The results obtained by the total income obtained by farmers in chili farming with an average income of Rp.35,124,800.-The total income earned by farmers in chili farming with an average income earned is Rp.25,204,800,- Chilli Farming in the Village of Kaligambir is worth the effort by looking at the $\mathrm{R} / \mathrm{C}$ ratio of 2.54, which means that each expenditure of Rp.100.- will receive Rp.254.-.
\end{abstract}

Keywords: chili, farming, feasibility

Abstrak. Indonesia adalah negara agraris, salah satunya menghasilkan komoditas cabai yang dapat mendukung perekonomian di negara ini. Cabai adalah salah satu jenis hortikultura yang tidak dapat ditinggalkan oleh masyarakat dalam kehidupan sehari-hari. Selain itu, usahatani cabai memiliki prospek yang sangat bagus. Tujuan penelitian ini adalah untuk mengetahui pendapatan, pendapatan yang diperoleh petani dalam satu musim tanam, dan kelayakan usahatani cabai dalam satu musim. Hasil yang diperoleh dengan total pendapatan yang diperoleh petani dalam usahatani cabai dengan pendapatan rata-rata $\mathrm{Rp}$. 35.124.800.-. Total pendapatan yang diperoleh petani di pertanian cabai dengan pendapatan rata-rata yang diperoleh adalah $\mathrm{Rp}$. 25.204.800, -. Pertanian Cabe di Desa Kaligambir sepadan dengan usaha dengan melihat rasioR / C 2,54, yang berarti bahwa setiap pengeluaran sebesar Rp.100, -akan menerima Rp.254, - .

Kata Kunci: cabai, pertanian, kelayakan

\section{PENDAHULUAN}

Indonesia merupakan negara agraris dengan sumber daya alam yang sangat mampu menopang perekonomian negara. Oleh karena itu, negara ini tidak bisa terlepas dari sektor pertanian yang menjadi roda penghasilan sebagian besar penduduk Indonesia. Sektor pertanian memegang peranan strategis dalam pembangunan perekonomian baik nasional maupun daerah. Pembangunan pertanian meliputi sektor tanaman pangan dan hortikultura, perkebunan, kehutanan, perikanan dan peternakan dengan tujuan untuk meningkatkan kesejahteraan masyarakat (Sihotang B, 2010). Komoditas hortikultura merupakan komoditas potensial yang mempunyai nilai ekonomi tinggi serta memiliki potensi untuk terus dikembangkan. Sisi permintaan pasar, jumlah penduduk yang besar, kenaikan pendapatan, dan berkembangnya pusat kota-industri-wisata, serta liberalisasi perdagangan merupakan faktor utama yang mempengaruhi permintaan.

Tanaman cabai (Capsicum annuum) adalah tanaman yang sangat penting secara ekonomi dan dibudidayakan secara komersial di Cina, Korea, Hindia Timur, Amerika Serikat, dan banyak negara lain termasuk di Indonesia (Ferrara et al. ,2011). Tanaman cabai merupakan salah satu komoditas hortikultura yang memiliki nilai ekonomi penting di Indonesia (Herlina, 2010). Seiring dengan berkembangnya industri pangan nasional, cabai merupakan salah satu bahan baku yang dibutuhkan dan banyak diusahakan oleh produsen dalam berbagai skala usahatani (Santika, 2008). Selain itu, 
cabai (Capsicum annum L.) juga merupakan salah satu sayuran yang permintaannya cukup besar, baik permintaan untuk pasar domestik maupun untuk ekspor ke mancanegara, seperti Malaysia dan Singapura (Sembiring 2009). Menutut Asravor, et al. (2016) menyatakan bahwa petani cabai pada umumnya harus dapat membuat keputusan yang baik sehubungan dengan alokasi input daripada keputusan yang baik mengenai konversi input menjadi output yang sempurna. Selain itu cabai rawit merupakan tanaman sayuran yang sangat penting, mengingat fungsinya untuk menambah rasa pada makanan yang dikonsumsi oleh sebagian besar orang Indonesia. Dengan berbagai kegunaannya, cabai merah dianggap sebagai salah satu komoditas esensial dengan nilai ekonomi tinggi. Selain digunakan sebagai bumbu masakan di tingkat rumah tangga, cabai merah juga digunakan sebagai bahan dalam berbagai industri pengolahan makanan dan minuman, serta dalam pembuatan obat-obatan dan kosmetik (Mariyono, 2016).

Di Jawa Timur Jumlah produksi cabai pada lima tahun terakhir yaitu pada tahun 2014 mencapai 238.820 ton, pada tahun 2015 mencapai 250.007 ton, pada tahun 2016 mencapai 260.803 ton, sedangkan pada tahun 2017 mencapai 260.803 ton, kemudian pada tahun 2018 mencapai 10.147 ton (Badan Pusat Statistik dan Direktorat Jenderal Hortikultura, 2014). Kabupaten Blitar merupakan salah satu sentra cabai di Jawa Timur. Luas lahan cabai yang siap panen saat ini di Kabupaten Blitar mencapai 6.950 ha dan produktivitas varietas cabai lokal Blitar mencapai 8 ton per ha. Lokasinya terletak di 3 kecamatan yaitu Kecamatan Panggungrejo seluas 3.000 ha, Binangun 2.500 ha, dan Wates 1.450 ha (BPS, 2018).

Desa Kaligambir Kecamatan Panggungrejo merupakan salah satu Desa di Kabupaten Blitar yang memiliki potensi serta memiliki sumber daya yang sangat menunjang untuk melaksanakan usahatani cabai. Hal ini dipengaruhi oleh peranan petani dalam mengelola usahataninya yang ditunjang dengan sistem irigasi dalam pengairannya yang sangat memadai serta siap untuk diolah untuk ditamanami cabai rawit.

Masalah yang sering dihadapi petani dalam usaha tani cabai adalah fluktuasi harga dan factor alam. Faktor alam dipengaruhi oleh cuaca yang tidak mendukung seperti hujan yang terus menerus dapat membuat cabe cepat busuk, selain cuaca juga disebabkan oleh serangan hama yang dapat membuat hasil panen cabe menurun karena cabe banyak yang busuk sehingga disinyalir pendapatan petani juga akan turun. Menurut Asravor et al. (2016) bahwa tantangan rendahnya produktivitas di pertanian cabai dapat dikaitkan dengan beberapa kendala utama yang menghambat pencapaian potensi. Kendala tersebut dapat mencakup serangan hama dan penyakit, terbatasnya lahan, harga produk yang rendah, rendahnya adopsi teknologi budidaya cabai dan ketidakefisienan yang timbul dari alokasi sumber daya produksi. peningkatan produktivitas pertanian cabai tidak dapat mengabaikan identifikasi dan mengatasi faktor-faktor cuaca, harga serta hama penyakit. Sebagai akibat dari kurangnya akses ke sumber daya produktif, ditambah dengan rendahnya tingkat adopsi peningkatan teknologi produksi cabai, peningkatan efisiensi pertanian cabai telah menjadi yang terpenting untuk meningkatkan tingkat produktivitas pertanian cabai Wosor DK, Nimo F (2012).

Mengacu pada uraian diatas maka tujuan penelitian ini adalah untuk mengetahui penerimaan, pendapatan yang diperoleh petani dalam satu kali musim tanam, dan untuk mengetahui kelayakan pada usahatani cabe rawit dalam satu kali musim tanam di Desa Kaligambir Kecamatan Panggungrejo Kabupaten Blitar.

\section{METODE}

\subsection{Lokasi dan Waktu penelitian}

Penelitian ini dilaksanakan di Desa Kaligambir Kecamatan Panggungrejo Kabupaten Blitar. Lokasi penelitian dipilih secara sengaja (purposive) dengan pertimbangan bahwa Desa Panggungrejo merupakan salah satu sentra produksi cabai rawit, karena sebagian besar masyarakat sebagai petani cabai rawit, bahkan memiliki produktivitas tertinggi di Kabupaten Blitar. Penelitian ini dilaksanakan pada bulan Nopember sampai dengan Desember 2020.

\subsection{Penentuan Sampel}

Penentuan responden dalam penelitian ini dilakukan dengan metode sampel acak sederhana (Simple Random Sampling method), dimana unsur dalam semua populasi mempunyai kemungkinan yang sama untuk menjadi sampel peneliti (Sudrajat 2002). Jumlah yang digunakan dalam penelitian ini sebanyak 35 KK petani cabai rawit. 


\subsection{Metode Pengumpulan Data}

Data yang digunakan dalam penelitian ini bersumber dari data primer dan data sekunder. Pengumpulan data primer dilakukan dengan cara observasi dan wawancara langsung dengan menggunakan daftar pertanyaan (quessionaire), sedangkan data sekunder diperoleh dari literatur literatur dan instansi yang ada kaitannya dengan penelitian ini.

\subsection{Metode Analisa Data}

Biaya total dihitung dengan cara menjumlahkan biaya tetap (Fixed Cost/ FC) dengan biaya variabel (Variable Cost/ VC) dengan menggunakan rumus: TC $=\mathrm{FC}+\mathrm{VC}$. Analisis Pendapatan adalah selisih antara penerimaan (TR) dan biaya total (TC) dan dinyatakan dengan menggunakan rumus : $\mathrm{Pd}=\mathrm{TR}-$ TC (Soekartawi , 2007), sedangkan untuk menghitung R/C menggunakan rumus menurut adalah perbandingan antara penerimaan dengan biaya total, dinyatakan dengan menggunakan rumus : Penerimaan Total R/C= Biaya Total (Noor, 2007).

\section{HASIL DAN PEMBAHASAN}

\subsection{Identitas Responsen}

Jumlah responden dalam penelitian ini berjumlah 35 orang terdiri dari 29 responden berjenis kelamin pria dan 6 responden berjenis kelamin wanita. Dalam penelitian ini petani cabai wanita lebih sedikit daripada petani cabai pria hal ini disebabkan adanya asumsi bahwa petani cabai wanita seringkali dianggap tidak produktif dibandingkan dengan petani cabai laki-laki. Penelitian ini sejalan dengan Amewu dan Onumah (2015) yang menemukan petani padi laki-laki NERICA secara alokasi lebih efisien daripada rekan perempuan mereka. Akan tetapi penelitian ini bertentangan dengan penelitian Onumah et al. (2013) yang menyatakan banyak dari tenaga kerja yang diperlukan untuk operasi pertanian (penyiangan, pemindahan, panen, pengolahan, dll) dipasok oleh perempuan. Hal ini karena tanaman cabai sangat sensitif, sehingga membutuhkan perawatan dan kesabaran dalam merawat tanaman cabai dan ini dilakukan lebih baik oleh wanita daripada pria. Di sisi lain, petani laki-laki yang mungkin sebagian besar adalah kepala rumah tangga mereka masing-masing mungkin ingin meminimalkan biaya untuk menghemat uang untuk pemeliharaan keluarga tani mereka dan dengan demikian dapat berakhir berproduksi dengan biaya minimum yang dapat dicapai.

\subsection{Umur}

Umur responden berkisar antara 28 sampai 57 tahun, dengan demikian seluruh responden berusia produktif. Hal ini sesuai dengan pendapat Anjayani dan Haryanto (2009) yang menyatakan bahwa penduduk usia produktif adalah penduduk berumur 15 sampai 59 tahun. Karena pada usia 28 sampai 57 tahun responden dianggap cenderung lebih mudah menerima inovasi yang akan membawa pengaruh baik terhadap peningkatan pendapatan usaha taninya. Umur petani cabai sangat mempengaruhi proses usahatani yang dijalankan dan hasil akhir yang akan dicapai. Hal ini sejlan dengan penelitian Amewu dan Onumah (2015) yang menyatakan bahwa usia petani cabai memiliki hubungan positif dengan inefisiensi teknis, yang menyiratkan bahwa petani berusia kurang efisien dibandingkan dengan anak-anak mereka. Hal ini sependapat dengan temuan Asante et al. (2014), Mariano et al. (2011) dan Khan dan Saeed (2011). Implikasi dari temuan ini adalah bahwa kebijakan yang bertujuan membujuk tim pemuda agar mau berbudidaya cabai harus dilaksanakan karena memiliki potensi untuk meningkatkan produksi cabai. Yang mengejutkan, petani cabai yang berpengalaman ternyata kurang efisien secara teknis dan alokasi dari pada rekan-rekan mereka yang tidak berpengalaman.

\subsection{Pendidikan}

Pendidikan responden bervariasi antara responden responden yang satu dengan responden yang lainnya mulai dari yang berpendidikan SD (Sekolah Dasar), SLTP (Sekolah Lanjutan Tingkat Pertama, SMA hingga kuliah. Sebagian besar responden tamatan Sekolah Dasar (SD) yaitu sebanyak $42.85 \%$, tamatan Sekolah Lanjutan Tingkat Pertama (SLTP) sebanyak 28.57 \%, tamatan Sekolah Menengah Pertama (SMA) sebanyak 22.85\%, dan tamatan Sekolah Tinggi (S1) sebanyak 5.71\%. Tingkat pendidikan merupakan faktor yang menentukan dalam kemampuan seorang petani mengadopsi teknologi. Dengan tingginya pendidikan seseorang petani akan dapat dengan mudah menerima inovasi-inovasi baru dalam hal kemajuan usahataninya. Hal ini sejalan dengan penelitian 
Schreinemachers (2016) yang menyatakan bahwa para petani yang lebih terlatih, lebih banyak berpengalaman dalam usahatani, berpendidikan tinggi akan lebih baik dan lebih sering menjadi anggota petani dalam organisasi-organisasi yang berorientasi terhadap kemajuan dalam berusahatani, sehingga dapat dengan mudah menerima inovasi ataupun teknologi baru yang akan diterapkan dalam setiap usahatani mereka. Tingkat pendidikan yang rendah akan mengakibatkan daya serap petani terhadap perkembangan teknologi menjadi lambat, sehingga terjadi kesulitan dan membutuhkan waktu yang lama untuk mengadopsi hal-hal yang baru.

\subsection{Pengalaman Berusaha}

Pengalaman yang dimiliki seseorang pada umumnya akan mempengaruhi proses pengambilan keputusan. Keadaan responden berdasarkan pengalaman menjadi petani cabai merah responden berkisar antara 5 sampai 20 tahun. Sebagian besar petani cabai di Desa Panggungrejo sudah berpengalaman menjadi petani cabai merah kurang $\leq 10$ tahun yaitu 13 orang $(37,14 \%)$ dan petani cabai merah yang berpengalaman lebih $>10$ tahun yaitu 22 orang $(62,85 \%)$. Petani cabai rawit yang mempunyai pengalaman lebih lama dalam berusahatani belum tentu selalu berhasil dalam menjalankan usaha taninya. Hal ini sejalan dengan pendapat Asante et al. (2014) yang menyatakan bahwa petani cabai yang berpengalaman ternyata kurang efisien secara teknis dan alokasi dari pada rekan-rekan mereka yang tidak berpengalaman. Hal ini mungkin disebabkan oleh fakta bahwa sebagian besar petani yang berpengalaman mungkin cenderung hanya mengandalkan pengetahuan mereka dan mungkin tidak mencari layanan konsultasi dari petugas penyuluh dan ini dapat menyebabkan ketidakefisienan mereka dibandingkan dengan rekan-rekan mereka yang tidak berpengalaman yang mungkin bersedia untuk mencari saran penyuluhan.

\subsection{Analisis Usahatani}

Prasetya (2006) menyatakan usahatani adalah ilmu yang mempelajari norma-norma yang dapat dipergunakan untuk mengatur usahatani sedemikian rupa sehingga dapat diperoleh pendapatan setinggi-tingginya. Analisis Pendapatan Usahatani cabai rawit penelitian ini dimaksudkan untuk mengetahui besarnya pendapatan yang diperoleh petani cabai di Desa Kaligambir selama satu musim tanam dengan cara menghitung selisih antara penerimaan dengan total biaya yang digunakan dalam usahataninya. Secara rinci tentang biaya, penerimaan dan pendapatan etani cabai rawit dalam satu kali panen dapat dilihat pada Tabel 1 .

Tabel 1. Produksi, Biaya dan Pendapatan Usahatani Cabai

\begin{tabular}{|l|r|}
\hline \multicolumn{1}{|c|}{ Keterangan } & Rp/Ha \\
\hline Produksi rata-rata /Kg & 605,6 \\
Harga (Rp/Kg) & 58.000 \\
\hline Total Penerimaan & $\mathbf{3 5 . 1 2 4 . 8 0 0}$ \\
\hline Biaya Tetap: & 1.600 .00 \\
Sewa Lahan & 700.000 \\
Pajak & 1.060 .000 \\
Penyusutan alat & $\mathbf{3 . 3 6 0 . 0 0 0}$ \\
\hline Total Biaya Tetap & \\
\hline Biaya Variabel: & 3.000 .000 \\
Tenaga kerja & 400.000 \\
Benih & 360.000 \\
Pupuk kandang & 700.000 \\
Pupuk buatan & 1.950 .000 \\
Pestisida & 150.000 \\
Polibek & $\mathbf{6 . 5 6 0 . 0 0 0}$ \\
\hline Total Biaya Variabel & $\mathbf{9 . 9 2 0 . 0 0 0}$ \\
\hline Total Biaya & $\mathbf{2 5 . 2 0 4 . 8 0 0}$ \\
\hline Pendapatan & $\mathbf{2 . 5 4}$ \\
\hline Nilai R/C & \\
\hline
\end{tabular}

Berdasarkan Tabel 1, di atas, maka diketahui penerimaan petani cabai rawit dalam satu kali musim tanam sebesar Rp. 35.124.800,00. Penerimaan yang di dapat petani cabai kali ini lumayan cukup besar, karena harga cabai terus mengalami kenaikan hampir setiap hari di sejumlah pasar tradisional Kabupaten Blitar. Saat ini harga cabai rawit yaitu naik hingga kisaran Rp. 58.000,00/Kg. 
Hal ini dikarenakan banyak cabai rawit petani busuk karena diserang jamur sehingga mengakibatkan panen dari petani mengalami penurunan sehingga peredaran cabai rawit dipasaran sangat sedikit yang mengakibatkan harga cabai melambung tinggi. Menurut Pandit (2018) petani harus bersatu untuk pemasaran kolektif dari produksi mereka dan mengembangkan strategi pemasaran untuk menghilangkan perantara untuk memperoleh pendapatan yang lebih baik. Dengan demikian diharapkan bahwa pertanian cabai merah dapat berkontribusi besar terhadap pendapatan petani (Geo \& Saediman, 2020).

Supriyono (2002) mengemukakan bahwa pengolahan biaya adalah proses mengelompokkan secara sistematis atas keseluruhan elemen yang ada kedalam golongan-golongan tertentu yang lebih ringkas untuk dapat memberikan informasi yang lebih mempunyai arti atau lebih penting. Biaya tetap adalah biaya yang relatif tetap jumlahnya dan terus dikeluarkan walaupun produksi yang diperoleh banyak atau sedikit. Jadi besarnya biaya tetap ini tidak tergantung pada besar kecilnya produksi yang diperoleh. Berdasarkan table diatas besarnya biaya tetap ini meliputi pajak sebesar Rp. 1.600.000,00/ha; sewa lahan sebesar Rp. 700.000,00/ha dan penyusutan sebesar Rp. 1.060.000,00/ha. Dengan demikian total rata-rata biaya tetap yang dikeluarkan petani responden adalah Rp. 3.360.000,00/ha

Biaya variabel adalah biaya yang terus dikeluarkan walaupun jumlah produksi yang dihasilkan banyak ataupun sedikit. Berdasarkan tabel diatas biaya variabel meliputi biaya polibag sebesar Rp. 150.000,00/ha, biaya benih sebesar Rp. 400.000,00/ha, biaya pupuk kandang sebesar Rp. $360.000,00 /$ ha, biaya pupuk buatan sebesar Rp. 700.000,00/ha, biaya pestisida sebesar Rp. $1.950 .000,00 /$ ha dan biaya tenaga kerja sebesar Rp. 3.000.000,00/ha. Rata-rata biaya variabel yang dikeluarkan oleh petani responden adalah sebesar Rp. 6.560.000,00/ha sehingga rata-rata total biaya sebesar Rp. 9.920.000,00/ha

Menurut Soekartawi (1995), pendapatan usahatani dapat diukur dengan menetapkan besarnya pendapatan yang diterima petani (selisih antara penerimaan dengan jumlah pengeluaran, baik yang berbentuk tunai maupun dalam bentuk faktor produksi). Rata-rata pendapatan petani responden adalah sebesar Rp. 25.204.800,00. Hal tersebut menunjukkan, nilai yang di dapat petani cabai rawit cukup besar. Jika pengelolaan usahatani tersebut dapat dilakukan dengan lebih intensif dan lebih efisien, maka semakin besar penerimaan, akan semakin besar pula pendapatan serta keuntungan yang diperoleh petani. Nilai pendapatan usahatani Cabai rawit cukup menguntungkan bagi petani, hal ini dapat dilihat dari nilai rata-rata $\mathrm{R} / \mathrm{C}$ yang diperoleh adalah sebesar 2,54 sehingga secara ekonomis menguntungkan dan layak untuk diusahakan. Tanaman cabai jika diusahakan dengan tepat akan dapat meningkatkan pendapatan para petani. Selain itu, cabai adalah tanaman bernilai tinggi (Athipanyakul dan Pak-Uthai, 2012). Hasil penelitian ini sejalan dengan hasil penelitian Saidah, et al. (2020) yang menyatakan bahwa tingkat keberhasilan pertanian juga ditentukan oleh nilai rasio $\mathrm{R} / \mathrm{C}$, yang merupakan rasio antara total pendapatan dengan total biaya produksi. Berdasarkan penelitian, dapat dilihat dari rata-rata $\mathrm{R}$ / C pada usahatani cabai merah pada musim kemarau sebesar 1,91 ini berarti bahwa pada setiap pengeluaran Rp 1,00 maka petani cabai merah akan menerima pendapatan $\mathrm{Rp} 1,91$ pada musim kemarau. Ini berarti bahwa budidaya cabai merah masih menguntungkan untuk dibudidayakan.

\section{KESIMPULAN}

Berdasarkan hasil dan pembahasan, maka dapat diperoleh kesimpulan bahwa total penerimaan yang diperoleh petani responden dalam usahatani Cabai rawit dengan rata-rata penerimaan yang diperoleh sebesar Rp. 35.124.800,00. Total pendapatan yang diperoleh petani responden dalam usahatani Cabai rawit dengan rata-rata pendapatan yang diperoleh adalah Rp. 25.204.800,00,-. Usahatani Cabai rawit di Desa Kaligambir, layak untuk diusahakan dengan melihat nilai R/C sebesar 2,54 yang artinya setiap pengeluaran sebesar Rp. 100.- akan memperoleh penerimaan sebesar Rp. 254-.

Petani diharapkan dapat terus meningkatkan produksi dan produktivitas, dengan memperluas lahan pertanian cabai rawit, dengan melakukan pengolahan lahan dan pemupukan yang sempurna serta dapat menekankan biaya produksi agar dapat meningkatkan pendapatan usaha taninya. Selain itu. Dukungan dari Pemerintah berupa modal dan penyediaan sarana produksi untuk meningkatkan produksi usahataninya masih sangat dibutuhkan. 
DAFTAR PUSTAKA

Akhmad Sudrajat, 2002. Pengertian Pendekatan, Strategi, Metode, Teknik, Taktik, dan Model Pembelajaran, yang diakses dari http://psbpsma.org/content/blog/pengertian-pendekatanstrategi-metode-tekniktaktik-dan-model-pembelajaran.

Amewu S, Onumah EE (2015). Cost efficiency of NERICA producing households in Ghana: a modified non-neutral stochastic frontier analysis. Am. J. Exp. Agric. 9(6):1-13

Asante BO, Villano RA, Battese GE (2014). The effect of the adoption of yam minisett technology on the technical efficiency of yam farmers in the forest-savanna transition zone of Ghana. Afr. J. Agric. Resour. Econ. 9(2):75-90

Asravor, J., Onumah, E. E., \& Osei-Asare, Y. B. (2016). Efficiency of chili pepper production in the volta region of Ghana. Journal of Agricultural Extension and Rural Development, 8(6), 99-110.

Athipanyakul, T. and Pak-Uthai, W. 'Determinants of Good Agricultural Practices (GAP) Adoption in the Chili Production System in Northeastern Thailand: A case of Participatory Approach', International Journal of Environmental and Rural Development, Vol. 3, (2012) pp. 175-180.

Badan Pusat Statistik dan Direktorat Jenderal Hortikultura. 2015. Produktivitas Cabai Menurut Provinsi, 2010-2014. http://www.pertanian.go.id/ Kementrian Pertanian Republik Indonesia.

BPS, 2018. Blitar Dalam Angka. Kantor Statistik Propinsi Jawa Timur

FerraraA.LovelliS.Di TommasoT.PerniolaM.2011Flowering, growth and fruit setting in greenhouse bell pepper under water stressJ. Agron.101219.

Geo, L., Ariani, W. O. R., \& Saediman, H. 2020. Determinants and Profitability of Small-Scale Red Chili Production in Konawe District of Southeast Sulawesi.

Herlina. (2010). Minat Belajar. Jakarta: Bumi Aksara.

Khan H, Saeed I (2011). Measurement of Technical, Allocative and Economic Efficiency of Tomato Farms in Northern Pakistan. International Conference on Management, Economics and Social Sciences (ICMESS' 2011) Bangkok Dec., 2011.

Mariano MJ, Villano R, Fleming E (2011). Technical Efficiency of Rice Farms in Different Agroclimatic Zones in the Philippines: An Application of a Stochastic Metafrontier Model. Asian Econ. J. 25(3):245-269.

Mariyono J, Integrated disease management for chili farming in Brebes and Magelang, Central Java: Social economic impacts. Jurnal Sosial Ekonomi dan Kebijakan Pertanian, 2016, 5(2): 114-124

Noor. Hendrifarial, 2007. Ekonomi Managerial. Raja Grafindo. Jakarta.

Onumah JA, Onumah EE, Al-Hassan RM, Bruemmer B (2013). Metafrontier analysis of organic and conventional cocoa production in Ghana. Agric. Econ. 6(59):271-280.

Pandit, B. H., Nuberg, I., Shrestha, K. K., Cedamon, E., Amatya, S. M., Dhakal, B., \& Neupane, R. P. (2019). Impacts of market-oriented agroforestry on farm income and food security: insights from Kavre and Lamjung districts of Nepal. Agroforestry Systems, 93(4), 1593-1604.

Prasetya. 2010. Analisis Efisiensi Ekonomi Penggunaan FaktorFaktor Produksi Pada Usahatani Melon di Kabupaten Grobogan. Surakarta. Fakultas Pertanian. Universitas Sebelas Maret.

Saidah, Z., Hartoyo, S., \& Asmarantaka, R. W. (2020, March). Change on Production and Income of Red Chili Farmers. In IOP Conference Series: Earth and Environmental Science (Vol. 466, No. 1, p. 012003). IOP Publishing.

Santika, A. 2008. Agribisnis Cabai. Penebar Swadaya, Jakarta.

Schreinemachers, P., Wu, M. H., Uddin, M. N., Ahmad, S., \& Hanson, P. (2016). Farmer training in off-season vegetables: Effects on income and pesticide use in Bangladesh. Food Policy, 61, $132-140$.

Sihotang,B. 2010. Kandungan Senyawa Kimia pada Pupuk Kandang Berdasarkan Jenis Binatangnya. Kumpulan Artikel Budidaya Tanaman http://pustaka .litbang .deptan.go.id/bppi/lengkap/bpp09037.pdf. $\sqrt{ }$

Soekartawi, A. 1995. Analisis Usahatani. Universitas Indonesia. Jakarta

Soekartawi, 2007. Teori Ekonomi Produksi. Rajawali Press. Jakarta.

Suprioyo. 2002. Macam-macam Biaya Usahatani. Penebar Swadaya. Bandung.

Wosor DK, Nimo F (2012). Resource use efficiency in Chili Pepper production in the Keta municipality of Volta Region of Ghana. Elixir Prod. Manage. 47(2012):8595-8598 